\title{
DOCTRINA
}

\section{Género y verdad. Valoración racional de la prueba en los delitos de violencia patriarcal}

\author{
Gender and truth. Rational system of proof in crimes of patriarchal violence
}

\author{
Marcela Paz Araya Novoa (iD \\ Universidad Austral de Chile
}

\begin{abstract}
RESUMEN Este artículo abordará las dificultades probatorias que en la mayoría de los casos exhiben los delitos de violencia contra las mujeres. Para ello, se tomarán en consideración los momentos o fases de la actividad probatoria judicial y el impacto que tendría en este iter «juzgar con perspectiva de género» como herramienta metodológica. En este contexto, se analizarán propuestas de mitigación a las dificultades que envuelven los problemas apuntados, lo que no implica prescindir del estándar de prueba o de la prueba ilícita, sino efectuar interpretaciones que, desde ese enfoque, contribuyan al acierto de la decisión.
\end{abstract}

PALABRAS CLAVE Momentos de la actividad probatoria, dificultades probatorias, delitos de violencia contra las mujeres, perspectiva de género, valoración racional.

ABSTRACT This paper addresses the evidentiary difficulties that most cases offences against women raise. For such a goal it considers the different evidence and proof stages and the effect that the so-called "gender perspective» as methodological tool could have in each of them. In that context, this work analyses some proposal to mitigate the problems found, without give up some guarantees such as the standard of proof and the exclusion of illegally obtained evidence, but making some interpretations which contribute to the success of the decision.

KEYWORDS Evidence activity moments, evidence difficulties, crimes of violence against women, gender perspective, rational valoration. 


\section{Introducción}

Hace un tiempo, surgió muy intensamente una reivindicación que resuena con gran vigor en los ámbitos jurídicos: el mandato urgente e ineludible de juzgar con perspectiva de género. Como señala Yanira Zúñiga, la popularidad de la expresión «género» ha trasformado esta categoría conceptual en el verdadero rótulo que se utiliza para nombrar a la tradición de pensamiento de la cual proviene, es decir, el feminismo (Zúñiga, 2013: 193). Así, pretendo incorporar al feminismo en el análisis de la valoración racional de la prueba en los delitos que reclaman actual e ineludiblemente la incorporación de esta mirada.

Para poder avanzar en las ideas que deseo estructurar en este artículo, es insoslayable efectuar un acercamiento a lo que implica la mentada perspectiva de género $\mathrm{y}$ su vinculación con las teorías feministas, lo que solo tiene sentido si partimos reconociendo la indeseable existencia de una desigualdad material entre hombres y mujeres que aún pervive en nuestra sociedad. Es en ese contexto que el género puede definirse como el «conjunto de prácticas, creencias, representaciones y prescripciones sociales que surgen entre los integrantes de un grupo humano en función de una simbolización de la diferencia anatómica entre hombres y mujeres» (Lamas, 2002:134) o «como aquellos comportamientos, actividades y atribuciones socialmente construidos que una sociedad concreta considera propios de mujeres o de hombres y que pueden contribuir a que la violencia contra la mujer se considere aceptable» (Rueda, 2018:14).

A la luz de lo anterior es que la perspectiva de género cobra su real significación y se presenta como una opción metodológica, es decir:

Una visión científica, analítica y política sobre las mujeres y los hombres, [que] propone eliminar las causas de la opresión de género como la desigualdad, la injusticia y la jerarquización de las personas basadas en el género. Promueve la igualdad entre los géneros a través de la equidad, el adelanto y el bienestar de las mujeres; contribuye a construir una sociedad en donde las mujeres y los hombres tengan el mismo valor, la igualdad de derechos y oportunidades para acceder a los recursos económicos y a la representación política y social en los ámbitos de toma de decisiones. ${ }^{1}$

Lo señalado se inscribe en la consigna de que, en la medida en que el feminismo es un proyecto emancipatorio que parte de la premisa de la existencia de una asimetría de estatus derivada de la construcción social de género, hablar de feminismo es, en realidad, hablar de igualdad. Más estrictamente, de una teoría sobre la igualdad (Zúñiga, 2013: 193).

1. Para más información, véase el artículo 5.9 de la Ley General de Acceso de las Mujeres a una Vida Libre de Violencia, primera sección Diario Oficial de la Federación mexicana, 1 de febrero de 2007, disponible en bit.ly/2ZMOfUm. 
De esta manera, el derecho como construcción social, realizado fundamentalmente por hombres, está inevitablemente teñido de sesgos androcéntricos y heteropatriarcales, aun cuando pretenda tener vocación de neutralidad, por lo que una de las aspiraciones de la perspectiva de género en el derecho es echar por tierra esta aparente neutralidad y servir de herramienta para comprender que la realidad no se puede analizar en forma neutra sin que ello, en situaciones de desigualdad, derive en perpetuar y consolidar la discriminación contra la mujer.

Estos sesgos están presentes - voluntaria o involuntariamente- tanto al momento de interpretar las normas como al valorar las pruebas, es decir, al momento de aplicar la ley. Es en este estadio en el que actualmente se centran los embates del feminismo a través de la perspectiva de género en el derecho. Si bien en otras épocas el feminismo planteaba denunciar las normas jurídicas creadoras de desigualdad o que producían el efecto de perpetuar la discriminación hacia las mujeres con el fin de que estas fueran derogadas y reemplazadas por otras que conjuraren estos efectos indeseados, actualmente busca «implementar en el enjuiciamiento técnicas jurídicas que faciliten la consecución de la igualdad efectiva de mujeres y hombres en el uso y disfrute de los derechos y libertades» (Subijana, 2018: 27).

Los efectos del feminismo y del enfoque de género que brevemente se han reseñado, están impactando tendencialmente toda la actividad jurisdiccional y dentro de ella, por cierto, la que consiste en la fijación de los hechos en el proceso judicial, a los cuales se ha de aplicar la consecuencia jurídica prevista por el derecho, existiendo en la actividad probatoria judicial variados tópicos que pueden ser adecuadamente abordados y revisitados desde la perspectiva en análisis.

Dicho lo anterior, la modesta pretensión del presente trabajo es abordar la situación de los delitos en que las víctimas son mujeres y que se producen a consecuencia de la asimetría histórica en las relaciones de poder entre los géneros. El objetivo central no es intentar hacer una interpretación global u holística de toda la problemática punitiva o de todas las instituciones ínsitas en el juzgamiento penal en este tipo de ilícitos, sino únicamente aproximarme desde la óptica de la mirada de género y la pretendida igualdad que esta herramienta reclama a algunos tópicos de la institución probatoria en la concepción racional de la prueba.

Para el propósito anunciado, no puedo dejar de mencionar que la actividad probatoria judicial se desenvuelve inevitablemente en contextos de incertidumbre fáctica, lo que implica que en la decisión que se adopte por parte del juez de los hechos siempre existirá margen para decisiones equivocadas. Es en honor a este ejercicio de sinceridad que en mi análisis recojo el compromiso epistemológico del proceso, lo que implica reconocer que la actividad probatoria en el proceso judicial tiene como finalidad la búsqueda de la verdad sobre lo ocurrido o, en términos más modestos, minimizar la posibilidad de errores. 
Las particularidades que exhiben los delitos de violencia patriarcal, como contextos de sumisión, sentimientos de ambivalencia en la víctima, la existencia de relaciones afectivas y el hecho de que generalmente los sucesos tienen lugar en espacios cerrados, de intimidad y sin espectadores, permiten sostener que la incertidumbre fáctica se ve amplificada, lo que minimiza la probabilidad de lograr el acierto en la decisión.

Con el objetivo de efectuar la lectura de las instituciones involucradas en la fijación de los hechos en el proceso judicial en esta clase de delitos desde la perspectiva de género, creo que es ineludible recurrir a los tres momentos de la actividad probatoria en el proceso judicial (Ferrer, 2007: 66), es decir, la formación del conjunto de elementos de juicio, la valoración en sentido estricto y el momento de la decisión sobre los hechos probados, los que si bien no se presentan puros y diferenciados en el tiempo, pudiendo entrelazarse y combinarse, su distinción metodológica es en extremo útil y sirve para comprender de mejor manera la actividad valorativa e incluso, podría sostener, tiene implicancias prácticas notables.

\section{La conformación del acervo de prueba}

En el derecho continental en los sistemas que han abrazado la libertad probatoria, la estrategia mayoritaria, para lograr el acierto de la decisión desde el punto de vista epistémico, implica la admisión de toda prueba potencialmente relevante (Bayón, 2008: 5-6), lo cual está estrechamente vinculado al primer momento de la actividad probatoria, que es el referido a la conformación de los elementos de juicio.

Los autores están de acuerdo con que, en este primer momento, cuando se trata de decidir qué elementos de prueba pueden ser empleados en el proceso, el criterio fundamental es la relevancia, que puede ser conceptualizada como un estándar lógico de acuerdo con el cual los únicos medios de prueba que deben ser admitidos y tomados en consideración por el juzgador son los que mantienen una conexión lógica con los hechos en litigio, de modo que puede sustentarse en ellos una conclusión acerca de la verdad de esos hechos (Taruffo, 2008: 38).

Si el proceso tiene como finalidad la búsqueda de la verdad, siendo este un fin estructural, deberá propenderse al acopio de la mayor cantidad de pruebas relevantes. El principio general es que cualquier elemento de juicio relevante para la adopción de una decisión debe ser admitido como prueba en el proceso judicial. No obstante, el fin de la averiguación de la verdad no es el único que interesa al derecho o al proceso, ya que existen otros intereses que pueden contraponerse o erigirse en obstáculos a esta búsqueda, importando un efectivo sacrificio epistemológico (Laudan, 2005: 97). Entre estos intereses puede mencionarse la celeridad en la toma de decisiones, la protección de ciertas relaciones, como las de familia o profesionales, las garantías fundamentales, etcétera, las que imponen la exclusión de elementos de juicio relevantes del conjunto o acervo sobre el que se va a adoptar la decisión. 
El desarrollo del proceso judicial a través de la proposición y práctica de las pruebas debe permitir conformar un conjunto de elementos de juicio que apoyen o refuten las distintas hipótesis sobre los hechos del caso y, conforme a la teoría racionalista de la prueba, el conjunto de elementos de juicio debe ser lo más rico y completo posible, concretando el principio epistemológico que reza que a mayor cantidad de pruebas disponibles, mayor posibilidad existe de acercarnos a la verdad o acierto en la decisión. Lo anterior «es un corolario del reino de la epistemología en el proceso buscado por Bentham, del método «natural» de la prueba» (Ferrer, 2010:5).

Esta regla de racionalidad se estrella con la realidad en la gran mayoría de los casos en que el juzgamiento debe ser realizado con enfoque de género, es decir, con respecto a los delitos que se cometen contra las mujeres y que son un reflejo de arraigadas concepciones machistas, los que por sus particularidades se desarrollan habitualmente en espacios cerrados, en la intimidad y sin espectadores, generalmente en contextos de sumisión. En ellos, por lo tanto, ni la investigación ni la conformación del conjunto de prueba suele ser fácil, ya que lo normal será que la única prueba con que cuente el acusador sea el testimonio de la propia víctima, cuestión a la que se suma que la afectada puede estar aislada de potenciales fuentes de ayuda y sujeta a estrategias para silenciarla desplegadas por el agresor.

El panorama, como se puede advertir, no se evidencia alentador a fin de poder conformar un conjunto rico y variado de elementos de prueba que haga factible la condena del enjuiciado. Sin embargo, acá no terminan las dificultades, ya que se presentan obstáculos no atribuibles a las características de los hechos, sino que con anclaje en la discriminación de género que permea ineludiblemente al proceso judicial. De esta manera, por la doctrina se han identificado (Di Corleto y Piqué, 2017: 410 y ss.) cuatro nudos problemáticos.

En primer término, todavía se advierten resabios de la concepción según la cual el Estado no puede intervenir en estos conflictos que están reservados al ámbito de lo privado, vinculados a la vida familiar o con lo sexual. Si bien reconocen que ha existido una tendencia a dejar atrás la retórica de lo privado (sobre todo en buena parte de los países latinoamericanos que han suscrito la Convención de Belém do Pará), ${ }^{2}$ todavía quedan resabios en la administración de justicia y dan lugar a investigaciones penales incompletas y sesgadas.

En segundo lugar, como lo he adelantado, en el derecho y especialmente en el derecho penal existen reglas en apariencia neutrales, que tienen como destinatario un sujeto sin género, con omisión de la experiencia y perspectiva de las mujeres, las que al ser aplicadas a casos de violencia de género pueden tener un efecto discriminatorio, lo que potencialmente impactará al momento de la recolección de

2. Convención Interamericana para Prevenir, Sancionar y Erradicar la Violencia Contra la Mujer (Convención de Belém do Pará) de 1994. 
evidencias que formarán el acervo sobre el cual se adoptará la decisión en el juicio respectivo.

En tercer término, también pueden interferir provocando discriminación la existencia de prejuicios y estereotipos discriminatorios, como los rótulos o etiquetas de «mujer honesta», «buena madre», «mujer mendaz», «mujer fabuladora», «mujer retractada», «mujer con ánimo ganancial», ${ }^{3}$ entre otros, lo que puede determinar la inacción o desidia en el actuar de policías o fiscales al omitir la recolección de evidencias o la tardanza en dicha actividad con las consecuencia adversas en aquellos delitos en que es crucial el acopio de pruebas con la mayor celeridad posible, como ocurre con algunas pruebas biológicas en los casos de delitos sexuales.

En último lugar, la victimización secundaria a la que se ven sometidas las mujeres afectadas por este tipo de ilícitos igualmente socava la actividad probatoria, por ejemplo, la falta de espacios adecuados para la toma de declaraciones sin privacidad o la falta de profesionales idóneos que les presten apoyo o contención con el fin de que puedan efectuar declaraciones oportunas, completas y eficientes a la persecución penal o la excesiva e indiscriminada exposición mediática del caso cuando concita la atención pública, como el caso de Nabila Rifo Rifo, ${ }^{4}$ en que la expareja de la víctima la atacó brutalmente con dos bloques de concreto, hiriéndola de gravedad y ocasionando su ceguera después de arrancarle los ojos con una llave de automóvil. Este juicio fue muy publicitado, siendo objeto de seguimiento por canales de televisión que transmitieron en vivo partes del juicio oral realizado en contra del acusado e incluso se exhibió al aire el contenido del informe ginecológico de la víctima. Un canal de televisión fue objeto de sanciones por faltas a la ética por el Consejo Nacional de Televisión de Chile, lo que constituye un claro ejemplo de victimización secundaria, ya que en dicha actividad subyacía el enjuiciamiento con respecto a la moral sexual de la afectada.

Fue el caso de González y otras, Campo Algodonero con México el que introdujo un cambio de paradigma en la investigación y recolección de pruebas en delitos de violencia contra las mujeres. 5 Además, sentó las bases del deber de investigar con perspectiva de género, ya que se trató de casos ocurridos en 2001 en ciudad Juárez, una localidad fronteriza de México, en los que se denunció la desaparición de mujeres jóvenes cuyos cuerpos fueron encontrados en un campo algodonero. En estos crímenes hubo una impunidad directamente atribuible a la ausencia de investigación, ya que fundada en estereotipos de género la policía estimó que las jóvenes salían de

3. Para más información, véase Hopp (2017: 15-46).

4. Para más detalle, véase el caso Nabila Rifo Rifo, Tribunal Oral en lo Penal de Coyhaique, rit 1-2017. Además, véase Zúñiga (2018: 236-237).

5. Confrontar con el caso González y otras con México, Comisión Interamericana de Derechos Humanos, 16 de noviembre de 2009, disponible en bit.ly/2zuXaiv. 
noche, se iban con sus novios o no vestían de forma «apropiada», lo que motivó a los agentes policiales a desestimar la existencia de algún delito y a no investigar, ya que no resultaba importante ni urgente buscarlas o brindarles protección.

Paliativos a las dificultades en la recolección de las pruebas en los delitos de violencia de género

Las investigaciones en los casos de violencia machista, según se ha hecho patente, poseen características que le son inherentes y ello debe ser recogido y abordado en la existencia de actividad investigativa policial que comporte que la recolección de pruebas sea especialmente exhaustiva y completa.

Estas particularidades obligan al acopio de pruebas vinculadas con el contexto de los hechos:

En especial la violencia intrafamiliar no se constituye por una sucesión de actos puntuales, sino que tiende a ser un continuum que se prolonga en el tiempo y que se expresa de distintas formas (violencia sexual, física, psicológica, económica y simbólica), no todas ellas tipificadas penalmente (Di Corleto y Piqué, 2017: 418).

La búsqueda de prueba de contexto puede permitir que los investigadores amplíen los márgenes de los elementos de juicio que deben recopilar y a estar atentos a las evidencias que sean relevantes, es decir, aquellas que aportarán corroboración a la hipótesis acusadora, recolección que en estos casos no solo se limitará al particular hecho (día y hora determinados), sino también a las circunstancias que lo rodean, las que en otro tipo de ilícitos pudieran ser soslayadas, debiendo recogerlas y conservarlas adecuadamente con el fin de servir de prueba de incriminación.

Este especial contexto del que se ha hecho caudal puede ser corroborado por la existencia de denuncias previas con respecto a delitos de violencia de género entre las mismas partes o con respecto al agresor en el ámbito civil o penal, así como atenciones brindadas a la víctima en servicios públicos, centros de salud, atención psicológica o psiquiátrica. De la misma manera, se puede recabar prueba relativa a familiares cercanos, especialmente hijos comunes, que evidencien huellas o rastros de haber sufrido o presenciado maltrato sostenido en el tiempo, así como todo antecedente social, laboral, sanitario o educativo que pueda ser relevante para el esclarecimiento del hecho.

Tratándose de delitos violentos, resulta del todo procedente recoger las evidencias sobre los hechos que precedieron o fueron concomitantes al delito, al igual que el historial clínico sanitario de la afectada y, con respecto a la evidencia física, la celeridad en la investigación es clave, ya que la tardanza puede afectar su obtención y conservación. 
En los casos de interculturalidad o interseccionalidad, ${ }^{6}$ resulta imprescindible contar con un traductor idóneo, que conozca a cabalidad el idioma de la afectada, sus particularidades. Además, en los casos de capacidades especiales como el de mujeres sordas o sordomudas, se debe contar con un intérprete que permita transmitir con fidelidad su declaración con el fin de evitar la participación de personas sin el conocimiento y la capacitación necesaria para esta labor, cuya intervención puede producir la obtención de información de mala calidad que redunde en prueba inservible en el juicio oral.

\section{El caso de la prueba ilícita y el nuevo paradigma}

Este tópico se vincula muy estrechamente con el derecho a la prueba, el que según Picó i Junoy (2009: 110-119) reconoce un triple contenido escalonado: el derecho a la admisión de la prueba, el derecho a la práctica de la misma y el derecho a la valoración de la prueba practicada.

El primero se concreta en la necesidad de admitir toda prueba que, propuesta por alguna de las partes, respete sus límites. El segundo, que se manifiesta como corolario del primero, implica poder exigir la práctica de toda la actividad probatoria que haya sido admitida. Finalmente, el último, consecuencia de los dos anteriores, se origina en poder exigir la valoración judicial de la prueba que haya sido admitida y practicada, ya que en caso contrario se le estaría sustrayendo toda su virtualidad y eficacia.

El paradigma que analizaré se vincula directamente con la primera y segunda arista del derecho a la prueba, pero tiene repercusiones ineludibles en la tercera.

En mérito de las dificultades probatorias a las que se enfrenta el juzgamiento de los delitos en general y los de violencia contra la mujer en particular, lo óptimo será tender a obtener la mayor cantidad de datos probatorios posibles y extraer el máximo rendimiento de ellos con el fin de colmar los criterios que imponen los test de control epistemológico de las conclusiones probatorias, así como la satisfacción del elevado

6. La interseccionalidad o enfoque de interseccionalidad es el análisis de cómo interactúan en una persona o colectivo diferentes categorías de privilegio/discriminación. Así, para cada sociedad concreta, las condiciones de vida de una persona se deben interpretar atendiendo de forma combinada a su sexo/género, clase social, nacionalidad, raza/color, sexualidad, religión, discapacidad, edad/generaciones, entre otras. Por lo anterior, la interseccionalidad está estrechamente vinculada con los enfoques de ciclo vital/grupo etario, diversidad sexual e interculturalidad, por ejemplo. Esta perspectiva sirve de herramienta de análisis para comprender las desigualdades, sus causas y consecuencias estructurales y dinámicas, que surgen de la interacción de dos o más de estas categorías o ejes de subordinación. La interseccionalidad trata la forma por la cual el patriarcado, el racismo, el clasismo y otros sistemas de opresión crean desigualdades básicas que estructuran las posiciones relativas de las mujeres, razas, clases y otros. Esta definición fue elaborada a partir del documento «Orientaciones Técnicas Centros de la Mujer», Servicio Nacional de la Mujer y la Equidad de Género, 2015). 
y exigente estándar de prueba penal por el que la sociedad ha optado para entender derrotada la presunción de inocencia, a la vez que hacer operativo el primer elemento del derecho a la prueba y, consecuencialmente, todos los otros.

Entonces, el nudo de la cuestión en este acápite es dilucidar si la prueba obtenida con infracción de garantías fundamentales puede o no ser admitida y valorada como prueba de cargo contra el acusado con el fin de obtener una sentencia condenatoria en su contra, cristalizando de esta manera la pretensión punitiva del Estado y de la víctima que brega igualmente por la obtención de una sanción y, a su turno, si la inadmisión o ineficacia de la prueba ilícita vulnera garantías fundamentales de la víctima, constituidas por el derecho a la prueba como parte integrante de las garantías constitucionales de los litigantes.

La institución de la exclusión de prueba ilícita beneficia al acusado, quien debe soportar el peso del Estado en su contra en la persecución penal, la que debe efectuarse por medios lícitos sin incurrir en conductas que vulneren sus bienes jurídicos o, derechamente, obteniendo pruebas con infracción de sus garantías fundamentales, lo que a la luz de un derecho penal garantista reclama ineficacia. La perspectiva de género en esta materia, lejos de posiciones radicales de suprimir toda la institución de la prueba ilícita por contraponerse a otra garantía fundamental que es el derecho a la prueba, desde la vereda de la víctima, que a su turno pugna por lograr la satisfacción de sus pretensiones de obtener una condena, permite revisitarla e interpretarla en el sentido de reducir lo más posible los efectos de su inadmisibilidad e ineficacia, considerando la escasa evidencia que normalmente en este tipo de delitos se logra recoger.

En el sistema europeo de los derechos humanos no es posible identificar una doctrina clara sobre ilicitud probatoria, sin perjuicio de que los comentaristas de la Convención Europea de Derechos Humanos reconocen que la idea de «un proceso con todas las garantías evoca la cuestión de la prueba ilícitamente obtenida» (Jara, 2012: 400 y ss.). Para Armenta (2011), no obstante la falta de reglas sobre admisión o ineficacia de la prueba, la ilicitud probatoria se incardinaría directamente en el artículo 6 de la Convención Europea de Derechos Humanos, ya que en su numeral 6.2 exige que la culpabilidad se establezca legalmente, concluyendo que es preciso examinar si en el conjunto el acusado ha disfrutado de un proceso equitativo. De esta forma, agrega:

La perentoriedad de acudir siempre a la valoración conjunta de la prueba, lícita e ilícita, y a partir de ahí, alcanzar el correcto enjuiciamiento sobre la eventual vulneración del derecho a un proceso justo en el que la condena del acusado resulte fruto de un proceso de tales características (Armenta, 2011: 158).

Es decir, la ineficacia de la prueba ilícita no se produce instantáneamente, sino que impone un ejercicio de ponderación conjunta de todos los datos disponibles y de su necesaria conclusión, en el sentido de que la privación de su virtualidad probatoria 
se determine solo en el evento de afectación al debido proceso del acusado ante la inexistencia de un juicio justo.

La misma autora extrae de lo anterior y, mediante el aludido examen del proceso en su conjunto, estima que tendrían efecto excluyente: a) las pruebas obtenidas a partir de una provocación policial; b) los elementos de juicio obtenidos violando el derecho del acusado a permanecer en silencio; o c) las declaraciones de coimputados o las declaraciones fuera de juicio, no ratificadas.

Abonando la interpretación que se pretende poner de manifiesto, se releva la importancia del caso Schenk con Suiza del 12 de julio de 1988, en que el demandante asesinó a su mujer contratando un sicario, quien registró una llamada telefónica crucial para esclarecer la participación del mandante y que luego reveló a la policía. Así, el Tribunal Europeo de Derechos Humanos consideró que la violación no era de la entidad suficiente con el fin de justificar la ineficacia de la prueba así obtenida (Jara, 2012: 401). De este modo, la ineficacia de la prueba ilícita no se produce de manera acrítica y automática, sino que debe ser apreciada en conjunto con los demás elementos de juicio para sopesar si en definitiva se ha producido o no un juzgamiento justo.

Sobre el punto en análisis, se ha afirmado que actualmente en general se acepta que se debe reconocer el derecho de las partes a la prueba para que el derecho al debido proceso sea efectivo, pero que al momento de su aplicación este principio tropieza con muchas trabas (Taruffo: 2010: 57). El derecho a probar un hecho implica que las partes tienen la facultad de presentar todos los medios de pruebas relevantes y admisibles para apoyar su versión de los hechos en litigio, no obstante existen reglas de exclusión y las que establecen privilegios, que miran a la protección de valores e intereses judiciales y extrajudiciales que, en la práctica, constituyen un obstáculo a su aplicación en los sistemas en que el derecho a la prueba se reconoce como un aspecto esencial de las garantías constitucionales de las partes.

Radicalmente, Taruffo (2010:58) sentencia que:

Sin embargo, dado que el derecho a la prueba tiene rango constitucional, deberíamos inclinarnos a concluir que tiene que encontrarse un equilibrio favorable a la admisión de todas las pruebas relevantes de las que dispongan las partes, ya que otras razones procesales no deberían afectar el derecho fundamental de estas a la prueba, y mucho menos anularlo [...] Solo la protección de otro derecho constitucional o fundamental más importante podría justificar - tras la debida consideración por parte del tribunal- que se sacrificara el derecho a la prueba. ${ }^{7}$

Estos podrían ser criterios orientadores en los casos de violencia de género en que

7. Para más información, véase Aguilera (2018: 85 y ss.). Además, véase Cátedra de Cultura Jurídica, Jordi Ferrer. Volvamos a las bases del garantismo: Fines y alcances de las garantías, 24 de julio de 2017, disponible en bit.ly/3gsGd8S. 
se imponga el imperativo de ponderar la prueba en su conjunto para poder decidir por el juez de los hechos si a pesar de existir prueba ilícita, el proceso ha sido justo o, en otros términos, si se ha vulnerado la garantía del debido proceso al acusado. Además de, por otra parte, la posibilidad de reducir al mínimo el sacrificio de la garantía del derecho a la prueba, lo que ocurrirá solo en el evento de existir derechos constitucionales más relevantes en juego, lo que deja absolutamente fuera del debate los casos de torturas o de apremios físicos.

\section{La valoración probatoria. El momento de la racionalidad}

Terminada la conformación y la práctica de los elementos de juicio —normalmente en las audiencias de preparación de juicio oral y de juicio oral- es necesario adentrarnos en la valoración en sentido estricto y señalar que el razonamiento probatorio, en este momento, se vuelca a la epistemología y a la racionalidad, que sin perjuicio de estar presentes también en el primer y tercer momento de la actividad probatoria, aquí lo están con prescindencia de reglas jurídicas que predeterminen a priori un resultado.

La falta de regulación jurídica en este segundo momento constituye una fuerte tentación para que - cerrada la puerta - ingrese por la ventana el subjetivismo y se entienda como un momento ausente de toda regla, aun de las de naturaleza cognoscitiva, en que campee a su antojo el decisionismo del adjudicador, lo que debe ser desechado de plano. Así, la valoración de la prueba ha de concebirse como una actividad racional consistente en la elección de la hipótesis más probable (entendida como dotada de un grado de probabilidad suficiente) entre las diversas reconstrucciones posibles de los hechos. Los esquemas de valoración racional son, por consiguiente, esquemas probabilísticos.

Es decir, si el sistema jurídico establece un régimen de libre valoración de la prueba, entonces deberá valorarse el apoyo inductivo que cada elemento de juicio aporta a las hipótesis en forma individual y en conjunto, pero debe advertirse que la prueba es libre únicamente en el sentido que no está amarrada a normas jurídicas que predeterminen el resultado de esa valoración. No obstante, la operación que consiste en juzgar el apoyo empírico que un conjunto de elementos de juicio aporta a una hipótesis está sujeta los criterios generales de la lógica y de la racionalidad, es decir, a criterios epistemológicos:

El principio de libre valoración de la prueba no significa per se la asunción de una idea «científica» de la prueba o de la fijación de los hechos. La libre valoración significa valoración discrecional, por cuanto no vincula a la ley: cómo se «colme» después el ámbito del juicio de hecho que la ley no disciplina es en sí mismo un problema. [...] Si el principio de libre valoración, en sí mismo, no dice cuáles son los criterios de valoración que han de usarse, el modelo cognoscitivista de fijación de hechos sí 
que proporciona algunas claves sobre el particular: por una parte, proscribiendo algunos criterios de valoración; por otra, indicando el tipo de criterios que han de usarse (Gascón, 2004: 160).

Los criterios generales de racionalidad epistémica — reglas de la lógica, máximas de la experiencia y conocimientos científicos- operan haciendo posible el razonamiento probatorio inferencial. En este sistema, el modelo de corroboración de hipótesis al cual pueden ser reconducidos los principios de la lógica responde a la necesidad del proceso penal de recurrir a una lógica de la probabilidad inductiva, que no cuantifica ni calcula numéricamente la probabilidad, como los modelos matemáticos o estadísticos (Araya, 2018: 184 y ss.).

En él, la justificación de una proposición fáctica que describe un evento que no es directamente observable, se basa en la constatación directa de hechos que dados nuestros conocimientos acerca del mundo tendrían que haberse producido si esa proposición fuere verdadera. En el modelo de la inferencia inductiva se asume hipotéticamente la ocurrencia de un hecho para derivar, recurriendo a los conocimientos científicos y a nuestra experiencia previa del mundo, ciertos eventos que deberían haber tenido lugar (las evidencias), si es que ese hecho (a probar) efectivamente hubiese ocurrido, de modo que la constatación de estos eventos corrobora o atribuye probabilidad inductiva a la hipótesis de que el hecho a probar sucedió (Accatino, 2010: 127).

No obstante, la hipótesis que ha resultado corroborada es una explicación posible, pero no hay garantía de que se trate de la única explicación posible sobre los hechos.

\section{Generalizaciones empíricas: Máximas de experiencia y conocimientos científicos}

Las generalizaciones empíricas configuran la base o estructura molecular del razonamiento probatorio inferencial en el sistema de libre valoración. Sus dos tipos -máximas de experiencia y conocimientos científicos-cumplen el mismo papel, es decir, son leyes que conectan los elementos de prueba existentes con una hipótesis sobre los hechos, permiten pasar del dato conocido (las evidencias) al dato desconocido (el hecho a probar).

En el caso de las máximas de la experiencia, su fundamento no corresponde a una ley de carácter universal, sino que reflejan meras regularidades empíricas que establecen solo relaciones de probabilidad, es decir, que conforme a nuestra experiencia pasada, si las pruebas son verdaderas, es probable que también lo sea la hipótesis. Se ha señalado que:

Las máximas de la experiencia son enunciados descriptivos (verdaderos o falsos) por tanto cuya fundamentación es empírica. Llegamos a ellas a través de razonamientos generalizadores (que usan las reglas de racionalidad epistemológica) a partir del examen de casos particulares. Son necesarias para correlacionar los hechos 
probatorios y los hechos que hay que probar, pero no se trata de una necesidad lógica o inductiva: son necesarias como premisas de la inferencia probatoria, no como criterios metodológicos de racionalidad (González Lagier, 2018: 22).

En materia de delitos de violencia de género, resulta especialmente relevante el razonamiento probatorio del que se ha dado cuenta, ya que como he señalado la persecución penal se enfrenta a dificultades estructurales que le son inherentes, pero además a la existencia de sesgos heteropatriarcales y machistas que impregnan todo ámbito de la sociedad incluido el proceso judicial, por lo que resulta fundamental la elección de las máximas de experiencia de la que se va a servir el razonamiento inferencial, tanto en la valoración individual de los elementos de juicio como en la conjunta.

Así, debe asumirse con mucho rigor el empleo de generalizaciones empíricas depuradas y descartar aquellas que encubran meros prejuicios, arquetipos y preconcepciones sobre el rol ideal de la mujer en la sociedad, como lo examinamos en el caso Campo Algodonero en la etapa de conformación del conjunto de elementos de juicio. Pues bien, identificar estos estereotipos y erradicarlos del procedimiento inferencial otorga una dimensión práctica ineludible en esta etapa del iter valorativo a la perspectiva de género, siendo una de las principales herramientas para incorporar este análisis al juzgamiento en beneficio de la no discriminación de la mujer.

El Comité para la eliminación de la discriminación contra la mujer identifica los siguientes estereotipos de género que deben ser erradicados en los casos de violación: ${ }^{8}$ i) la víctima debía haber recurrido a toda su fuerza y su valor para resistirse a la violación y le privó de credibilidad el no haber tratado de escapar; ii) para ser violada con intimidación la víctima debe ser tímida o atemorizarse fácilmente; iii) cuando la víctima y el agresor se conocen, el acto sexual es consentido; iv) no puede haber oposición a la violación si el acusado logra eyacular. ${ }^{9}$ Además, en otro pronunciamiento, este organismo ha identificado como estereotipo de género la función reproductiva de la mujer. ${ }^{10}$

Con respecto a los primeros, Yanira Zúñiga sostiene lúcidamente que:

8. El Comité es el órgano de expertos independientes que supervisa la aplicación de la Convención sobre la eliminación de todas las formas de discriminación contra la mujer por sus Estados parte.

9. De hecho, la principal decisión del Comité en materia de tratamiento de la estereotipación de género es el caso Karen Tayag Vertido con Filipinas, que motivó la decisión del Comité para la eliminación de la discriminación contra la mujer/46/18/2008, concluyendo que el Estado incumplió su obligación de eliminar estereotipos de género al aplicar normas inflexibles sobre lo que las mujeres deberían ser o deberían haber hecho al ser víctimas de violación.

10. Decisión del Comité para la eliminación de la discriminación contra la mujer en el caso L.C. con Perú referido al caso de una niña de 13 años que queda embarazada a causa de una violación, quien se intentó suicidar arrojándose de un edificio, por lo cual requirió una operación urgente de columna y los servicios médicos decidieron retardar la operación hasta completar el embarazo involuntario. 
Otro ejemplo de la primacía del punto de vista masculino se relaciona con el rol que se asigna a la evaluación del comportamiento sexual previo de la víctima en la prueba de la violencia sexual. La imagen de que solo las mujeres vírgenes, púdicas o decentes son susceptibles de ser violadas, o la idea de que un «no» puede interpretarse como un «sí», o que un «sí» inicial inhabilita a la mujer para negarse posteriormente ante el avance sexual masculino, siguen influyendo, hasta el día de hoy, en la valoración judicial de la existencia de un delito sexual, porque expresan el imaginario masculino sobre el sexo y la violencia (Zúñiga, 2018: 227).

A los anteriores pueden agregarse los prejuicios que se erigen en muchos casos en máximas de experiencia, pero que no poseen un fundamento sólido y que encubren igualmente estereotipos de género, como las que señalan que la tardanza en hacer la denuncia por la mujer socava su credibilidad o es fundamento de lo inverosímil de la misma, o aquella que expresa que la víctima que se retracta de su denuncia carece de credibilidad, ya que no toman en consideración la posición de sometimiento en que muchas veces se encuentra la afectada con respecto al agresor o las implicancias que se derivan del fenómeno llamado la «rueda de poder y de control» (Sordi, 2018: 25), ${ }^{11}$ que explican este tipo de comportamientos. También puede mencionarse aquel que pone el énfasis en la ausencia de alteración emocional en la afectada al relatar los hechos materia de lo denunciado, es decir, la falta de correlación ideoafectiva, o aquel que toma en cuenta que la víctima no se aísla socialmente después de haber sufrido el delito, ya que no advierte el gran abanico de reacciones con que los seres humanos podemos enfrenar una situación compleja o traumática. Estas máximas prejuiciosas no consideran en lo más mínimo que la decisión de denunciar:

Precisa neutralizar o minimizar sentimientos tan poderosos, como lo reflejan las encuestas de victimización, como el temor a represalias, la vergüenza por lo sucedido, el riesgo de la estigmatización familiar y social, la culpa por lo sufrido, el miedo a someterse a un escrutinio público o el temor a no ser creídas» (Subijana, 2018: 34).

Con respecto a lo anterior, es muy clarificadora la declaración que presta la sargento segundo de Carabineros de Chile C. M. Z. ${ }^{12}$ en la causa seguida contra F.D.W. por denuncia calumniosa, quien sobre la notitia criminis que le correspondió recoger

11. «La rueda de Duluth o rueda de control [...] pone de manifiesto que la violencia es parte de un patrón de comportamiento que incluye la intimidación, los privilegios, el aislamiento emocional y el abuso económico» (Sordi, 2018: 25).

12. Testigo en el juicio sobre delito de denuncia calumniosa en que por sentencia del tribunal de fondo se condenó a la denunciante F.D.W., por cuanto la causa en que recayó su denuncia por delito de violación fue materia de un sobreseimiento definitivo. Este pronunciamiento fue revertido por la Corte Suprema chilena, quien acogió un recurso de nulidad interpuesto por la defensa y dictó sentencia de reemplazo absolviendo a la imputada. Causa RUC 1610021476-1, Rit 101-2008, del Tribunal del Juicio Oral en lo Penal de Puerto Montt. 
expresó: «Noté a la denunciante con hálito alcohólico, pero no en estado de ebriedad, se trasladaba por sus propios medios [...] No la vi afectada como una víctima de violación que he visto en otras oportunidades».

En el mismo juicio, el abogado de la parte querellante, con el fin de dar cuenta de la falsedad de la denuncia por violación, argumentó que la imputada y su representado - el querellante - se habían conocido por medio de la red social Tinder y que «todos sabemos que esa red social se utiliza a fin de buscar sexo».

El contenido de estas pseudo máximas de experiencia se relaciona directamente con el fundamento epistémico de las generalizaciones a que se recurre y de las teorías científicas en juego, que constituyen la garantía de un razonamiento judicial o de un razonamiento científico en general, del que fluye que estas generalizaciones solo son meras regularidades espurias, que no poseen soporte empírico sólido (Taruffo, 2008: 268 y ss.) y que obedecen a construcciones culturales arraigadas en el colectivo social fuertemente influenciado por el patriarcado, por lo que no pueden servir de sustento a una inferencia racionalmente justificable.

Por lo anterior, la utilización de las máximas de experiencia en la argumentación probatoria es del todo riesgosa, pero insoslayable. Por lo mismo, es necesaria una medida de control de esta actividad, que consiste fundamentalmente en exigir que los jueces saquen a la superficie - refloten - las máximas con las que justifican su decisión, con el fin de que pueda controlarse su eventual arbitrariedad o la consistencia y solidez de su basamento empírico, erradicando las que son un producto directo de estereotipos de género o que encubren concepciones discriminatorias.

En lo que concierne a los conocimientos científicos, al igual que las máximas de la experiencia actúan en el razonamiento probatorio como regla de conexión que permite pasar del dato conocido al desconocido. Por las particularidades de los ilícitos tratados, en los casos en que existan evidencias que puedan ser materia de peritajes científicos, la policía y los agentes encargados de la persecución penal deben ser especialmente cuidadosos y prolijos en su recolección y conservación, a fin de lograr obtener prueba de cargo de calidad y con basamento epistémico suficiente. Especial atención merece la llamada pericia de credibilidad del relato de la víctima, la que será tratada en lo sucesivo.

Así las cosas, resulta útil distinguir las máximas de la experiencia de los conocimientos científicos. Se ha sostenido que un rasgo distintivo entre las máximas de experiencia y los conocimientos científicos podría ser que:

Mientras que las reglas científicas aspiran a la universalidad, las máximas de la experiencia común se conforman más modestamente con la habitualidad (palabra más neutra que «normalidad»). Lo cual se traduce en que: mientras las reglas científicas no admiten excepciones (ante una excepción, la regla científica se abandona o se modifica), las máximas de experiencia común han de convivir con ellas (Igartua, 2004: 118). 
Entonces, es posible predicar que el rol de las máximas de experiencia en el razonamiento probatorio es similar al que cumplen los conocimientos científicos, solo que aquellas pueden identificarse con lo que, conforme a las vivencias del juez de los hechos o de quien invoca su aplicación, corresponde a lo que «normalmente» ocurre en el mundo, en cambio, los conocimientos científicos tienen pretensión de universalidad, de modo que si pierden esa característica pueden perder su carácter de científicos o transformarse en máximas de experiencia.

Todas las generalizaciones empíricas que se utilicen en la valoración probatoria en los delitos de violencia patriarcal deben necesariamente deshacerse de los prejuicios que perpetúan las relaciones desiguales de poder entre los géneros y que encierran estereotipos que, camuflados, se invocan o utilizan para realizar inferencias probatorias, como el de la mujer sexualmente disponible para cualquier hombre, por ejemplo, por tener hijos con distintos padres, o inducido de datos como su forma de vestir, su estado de embriaguez o el lugar y la hora en que se sitúan los hechos; como la contracara de aquellos de sesgo positivo, como el ser una buena esposa, buena madre o mujer decente. Estos mismos prejuicios heteropatriarcales deben ser identificados y derrotados cuando sirvan de sustento a la prueba pericial, determinen la tardanza en su realización o conlleven un trato discriminatorio al ser obtenidos directamente de la mujer como evidencia, pudiendo provocar la pérdida de información relevante o que esta sea de menor calidad.

\section{La credibilidad del testimonio de la víctima: Luces y sombras}

El espacio y las particularidades en que tienen lugar los delitos que se analizan, determinan que en muchos casos exista escasa prueba de cargo o que esta solo se reduzca al testimonio de la afectada, de modo que se afirma que de no aceptarse la suficiencia de este medio único se podría llegar a la impunidad. Por eso, han surgido voces que levantan consignas seductoras en orden a brindar un estatus especial al testimonio de quien ha padecido el ilícito como medio para obtener condenas, en muchos casos de gran envergadura.

En el ámbito de la valoración racional de la prueba, es preciso recordar que en lo concerniente a las pruebas personales y en especial a la prueba testimonial, se requiere de dos enjuiciamientos. El primero es el relativo a la credibilidad del testigo, que se dirige a saber si lo declarado por él es realmente lo que conoce, que no haya tenido errores de percepción o de memoria y que no tenga ánimo ganancial. El segundo está enfocado en calibrar la calidad informativa de los datos transmitidos, es decir, su adherencia a la realidad empírica. De esta forma, se afirma que las fases de la valoración aludidas:

Se necesitan recíprocamente, no hay valoración conjunta racional si previamente no se ha tomado en cuenta el valor de los distintos elementos que forman el conjun- 
to, como tampoco se puede otorgar una fiabilidad definitiva a cada fuente de prueba con independencia de la atribuida a las demás (Igartua, 2003: 254).

Sin perjuicio de que este doble enjuiciamiento está sujeto a la realización de inferencias que deben justificarse adecuadamente en la motivación de la sentencia, tratándose de la credibilidad de los testigos (incluida la víctima) se suele operar en base a intuiciones o percepciones que parecen ser producto de un «sexto sentido», que permite captar en clave, obviamente no técnica, esos matices propios del lenguaje gestual que el juez percibe desde la privilegiada posición que la inmediación propicia y que, por ello, solo él podría apreciar (Andrés Ibáñez, 2007: 167). Los elementos como la afectación emocional o la ausencia de ella, la seguridad al declarar, la palidez o el rubor, son datos que deben procesarse de la misma manera que los datos tomados de la realidad empírica a la luz de máximas de experiencia que puedan tener la virtualidad epistémica de brindar una conclusión racional y sólida, erradicando de esta fase igualmente las máximas machistas que solapan prejuicios y preconcepciones de cómo debería idealmente comportarse una mujer en determinado tránsito. ${ }^{13}$

Efectivamente, si bien puede predicarse que en virtud de la inmediación el tribunal está en una mejor posición epistémica para fiscalizar la veracidad de las declaraciones y que las partes están también en una posición privilegiada para evidenciar falsedades o animadversiones (porque se reduce el número de intermediarios en la transmisión de la información), con todo ha de considerarse que la apreciación que realiza el tribunal no es neutra, ya que está cargada de sesgos, emotividad, juicios, prejuicios o preconcepciones en el sentido apuntado que, de no mediar la obligación de explicitar el razonamiento de forma intersubjetiva, permanecerán en lo más profundo del fuero interno de quien es obligado a decidir sin que pueda ser adecuadamente controlado.

No se puede obviar en este tópico que el juez no observa directamente el hecho a probar y que lo que tiene es la percepción directa e inmediata del elemento de prueba que permite formar su juicio en orden a cómo ha ocurrido un determinado hecho. Así, el juzgador deberá efectuar inferencias a partir de la información aportada por los diversos medios de prueba, entre ellos los de carácter personal (testigos, víctima, peritos), procedimiento inductivo que no está exento de ambigüedades y errores.

13. No obstante, se ha sostenido que «estos prejuicios pueden operar en ambos sentidos, es decir, dando crédito desmesurado a la declarado por la víctima, en ciertos contextos, por lo que se ha indicado: Hay un tipo de supuestos en los que el modus operandi descrito se hace presente de la forma más visible y con un exuberante desarrollo de todas sus implicaciones negativas. Me refiero a los casos de una única prueba, la de la víctima-testigo de cargo que, tratándose de agresiones sexuales, dista mucho de ser un ejemplo de libro en la experiencia jurisdiccional [...] Cuando, lo que es frecuente, no hay otros datos que los aportados por la afirmación del o de la testigo y la negación del acusado, la ratio decidendi suele reducirse en la práctica a cuestión de mera credibilidad, en la clave esencialmente intuitiva a la que se ha hecho mención» (Andrés Ibáñez, 2007: 167-168). 
De ordinario se considera que la percepción de la prueba testimonial se produce de manera lineal casi por contacto, como efecto mágico de la inmediación. No obstante, se ha concluido que:

El recuerdo defectuoso no es la excepción, sino la regla y, por otra parte, el recuerdo del hecho puro no existe; un evento por haber sido percibido resulta automáticamente alterado por el «valor añadido» que le impone el receptor, al igual que los repetidos intentos de recuperación del suceso, cuando se llevan a cabo en distintos momentos, separados por lapsos relativamente largos, lo que contribuye a ejercer un efecto distorsionador de los contenidos mnésicos originales; que se verá acentuado cuando, además, se reciba información externa sobre el asunto como sucede en los interrogatorios, en los que las preguntas suelen ir cargadas de sugestiones implícitas (Andrés Ibáñez, 2007: 164).

Por otra parte, es muy plausible que el testigo, la víctima entre estos, no sea mendaz en su declaración, sino que aun actuando de buena fe proporcione al tribunal información de mala calidad o derechamente falsa por haber incurrido en errores en la apreciación o percepción de los sucesos sobre los que depone:

Una de las patologías, muy controvertidas en la epistemología del testimonio, se refiere a la mentira (en particular, a la definición de cuándo se produce esta). La forma más intuitiva de definir la mentira es la que figura tanto en el Código Penal brasileño como en el español: «hacer una afirmación falsa» 0 «faltar a la verdad». En la doctrina, por tanto, hay voces que afirman que «mentir en general implica decir algo que es falso».

No obstante, la definición anterior no parece precisa: alguien que tiene una información falsa y cree genuinamente en la verdad de esta puede transmitirla sin configurar con ello una mentira. Se trataría de un error sincero [...] Por tanto, el testimonio puede ser falso al menos de dos formas: «mediante mentiras o mediante errores sinceros (De Paula Ramos, 2019: 84-85).

Hace ya un tiempo, y a fin de revestir tanto de racionalidad como de objetividad a la valoración del testimonio único y consciente, al parecer, de las numerosas y disímiles dificultades aludidas con precedencia, el Tribunal Supremo Español ha venido fijando ciertos requisitos o, con más propiedad, parámetros o pautas orientativas con los cuales debe ser valorada la credibilidad del testimonio de la víctima. Así, la sentencia de la Sala Penal de 21 de marzo de 2011 (STS núm. 238/2011-RJ2011/2895), entre otras, ha señalado que la declaración de la víctima corresponde al tribunal juzgador que la presenció dentro de ciertas cautelas garantizadoras de su veracidad, que son:

- Ausencia de incredibilidad subjetiva que pudiera surgir de sus características físicas o de sus circunstancias personales relevantes: i) aquellas que pudieren debilitar su testimonio (como minusvalías sensoriales, psíquicas o psicológi- 
cas); ii) por la concurrencia de móviles espurios basadas en la relación anterior entre víctima y acusado, denotativas de odio o resentimiento, venganza o enemistad; y iii) ausencia de ánimo de proteger a un tercero u otro interés de cualquier índole.

- Verosimilitud del testimonio basada en la lógica de su declaración y el suplementario apoyo de datos objetivos, los que suponen la coherencia interna del relato o la plausibilidad de la declaración. Los datos objetivos de corroboración pueden ser muy diversos, como lesiones en los delitos en que se producen, manifestaciones de otras personas sobre hechos o datos que sin ser propiamente el hecho delictivo atañen a algún aspecto fáctico cuya comprobación contribuya a la verosimilitud de la declaración, peritajes sobre aspectos de igual valor de corroboración, etcétera (Montesinos, 2017:133).

- Persistencia en la incriminación, la que debe ser mantenida en el tiempo y carente tanto de ambigüedades como de contradicciones en lo esencial del relato en las sucesivas declaraciones del testigo.

Como se ha puntualizado, estas pautas no son requisitos taxativos en cuanto a que la ausencia de una de ellas invalida el testimonio de la víctima, sino criterios orientadores de la sinceridad del testigo y de su fiabilidad, las que constituyen el primer enjuiciamiento que debe realizar el juez de los hechos y que cumplido, le permite efectuar el segundo, que importa analizar el contenido de la declaración a fin de evaluar su adherencia a la realidad de los hechos enjuiciados. La concurrencia de todas o la ausencia de algunas no puede sustituir a la labor valorativa del juez de fondo, ya que es posible que el testigo, aun cuando tenga interés en el resultado del juicio (incluso el que desborde la natural expectativa de que el acusado sea condenado), puede ser veraz en sus declaraciones. Del mismo modo, en los casos en que la víctima haya variado sus declaraciones en algunos de sus extremos, puede suceder que de todos modos aporte datos relevantes y que se correspondan con la realidad de lo ocurrido.

Lo central de este punto es hacer presente que la credibilidad de los testigos, entre los cuales se encuentra la víctima, debe ser objeto de valoración racional, la que se despliega mediante el método de corroboración de hipótesis que recurre a las generalizaciones empíricas con el fin de extraer las hipótesis que cuenten con mayor basamento empírico. Todo esto debe ser adecuadp y completamente justificado en la motivación de la sentencia. A su turno, la fundamentación de la sentencia no puede ser entendida como el espejo de la psique del juzgador, sino una justificación en sentido estricto que impone dar razones que deben ser buenas razones de la razón por la que el juez le cree o no a la víctima, lo que posibilita el adecuado control de la decisión sobre la prueba (Araya, 2020: 105 y ss.). Lo anterior excluye lo subjetivo, los pareceres o impresiones sin sustento, es decir, lo incontrolable. 
En este tipo de delitos se recurre con frecuencia a los llamados peritajes de credibilidad del relato de las víctimas, realizados normalmente por profesionales del área de la psicología. Son estos profesionales quienes realizan una o más entrevistas estructuradas o semiestructuradas a las víctimas y sujetándose a determinados protocolos, concluyen la veracidad o falta de ella en la declaración de quienes son sujetos de la pericia:

Lo que se busca con estos medios de prueba es: establecer el grado en que cierto relato específico con respecto a los hechos investigados cumple, en mayor o menor grado, con criterios preestablecidos que serían característicos de relatos que dan cuenta de forma fidedigna con respecto a cómo sucedieron los hechos. Se trata de un informe psicológico que sirve como «apoyo periférico» o de mera corroboración, pero que no tiene un carácter definitivo, no sustituye la convicción sobre la credibilidad del testigo (Di Corleto y Piqué: 2017: 425).

Este tipo de pericias o informes, en el evento que se estimen procedentes, deben ser realizados con conciencia de su problemática y estrictamente en los casos en que existan dudas razonables sobre la credibilidad de la víctima, ya que su utilización automática y acrítica, aun cuando exista variada y contundente prueba de cargo, independiente de la declaración de la víctima, puede traer aparejada «una mirada prejuiciosa sobre las mujeres, en el sentido de que tienen razones para inventar o tergiversar los hechos denunciados» (Di Corleto y Piqué, 2017: 425), contribuyendo de esta forma, lejos de erradicarlos, a construir arquetipos como el de la mujer fabuladora, por cuanto estos elementos de prueba no son utilizados para medir la credibilidad de hombres víctimas de delitos, por ejemplo, contra la propiedad o incluso contra su integridad física, estableciendo así diferencias injustificadas y sin sustento racional.

Es necesario traer a colación, además de lo apuntado, que el mayor nudo problemático que posee la incorporación a juicio oral de los llamados «peritajes de credibilidad» es que se corre el peligro de sustituir al juez de los hechos en una de las actividades que son inherentes a la valoración de los elementos de juicio en el ámbito del sistema de sana crítica racional, es decir, el de la valoración individual de la prueba que implica determinar la fiabilidad del elemento en cuestión, lo que no debe ser deferido al perito, ya que constituye una de las aristas esenciales de la actividad jurisdiccional (Duce, 2010: 48). Por consiguiente, corresponde al juez determinar si la víctima es fiable, es decir, si ha tenido errores de percepción o de memoria, si está en condiciones de apreciar el hecho sobre el que depone, si tiene ánimo ganancial, etcétera, lo que debe ser evaluado a la luz del método inferencial ya referido. Constituye una dificultad adicional que el perito pueda sustituir al juez en cuanto a definir si la víctima resulta o no creíble, la opacidad relativa a la metodología utilizada en las llamadas ciencias humanas, lo que implica una traba al 
despliegue de la garantía del contradictorio, ya que se complejiza la posibilidad de cuestionar el método y, consecuencialmente, las conclusiones del experto. ¿Cómo y con qué se contrastan?

\section{Exigencia de corroboración mediante datos periféricos}

Esta pauta orientativa - de construcción jurisprudencial por el Tribunal Supremo español- que refuerza la credibilidad de la víctima y que consiste en el apoyo de datos contextuales, que le proporcionen valor de corroboración, nos remite en algunos casos a la utilización de las máximas de la experiencia que, aun cuando sean leídas en clave de perspectiva de género, representan un significativo problema en el razonamiento probatorio inferencial.

Preclaro sobre este punto, Juan Igartua sentencia:

¿Qué son las máximas de experiencia? Si nos representamos el razonamiento probatorio conforme al modelo silogista, la «máxima de experiencia» vendría a ser la premisa mayor - a menudo implícita - del susodicho silogismo; el «dato probatorio» disponible funcionaría como la premisa menor; y la conclusión constituiría el «hecho probado». Pondré un ejemplo banal, aunque no haga falta: «las madres aman a sus hijos» (máxima de experiencia), «Filomena es madre de Pascual» (dato probatorio) «Filomena ama a Pascual» (hecho probado).

\section{Y continúa:}

Esos juicios generales, es decir, las «máximas de experiencia», suelen extraerse - según se acostumbra a afirmar- del patrimonio científico o de la experiencia común, si bien a menudo se infiltran prejuicios (habitualmente bendecidos por el pensamiento moral y/o políticamente correcto) carentes del debido fundamento empírico (Igartua, 2004: 116).

Si bien el uso de las máximas de experiencia en el razonamiento probatorio no puede ser soslayado, no deben usarse irreflexivamente, sino con conciencia de su falibilidad, ya que responden al método de la inducción generalizadora o ampliativa, de las generalizaciones empíricas y, por ende, de su utilización jamás podremos obtener certezas, sino únicamente conocimiento probable. En ello no difieren de otras generalizaciones con mayor sustento epistémico, como ocurre con algunos datos obtenidos de conocimientos científicos. No obstante, las máximas de la experiencia no están dotadas de la misma eficacia explicativa, difiriendo enormemente en este punto unas de otras. Mientras algunas máximas de experiencia gozan de un alto grado de elaboración y reconocimiento, «otras serán el fruto de un reducido número de datos empíricos, e incluso tener necesidad de ser, a su vez, probadas» (Andrés Ibáñez, 2007: 206). 
Efectivamente, y en armonía con lo afirmado, la perspectiva de género exige que el relato que realiza la mujer afectada por el delito sea valorado erradicando estereotipos de género que:

Tratan de universalizar como criterios de racionalidad simples máximas de experiencia machistas; pero resulta esencial entender, complementariamente, que la perspectiva de género exige igualmente sustituir tales máximas de experiencia machistas, tradicionalmente asumidas, por nuevas máximas de valoración probatoria basadas en exigencias de igualdad real y efectiva en la interpretación, aplicación y resultado de la aplicación de la ley (Fuentes, 2020: 283).

Lo que obviamente debe desplegarse en el doble juzgamiento que consiste, como se señaló, en valorar la credibilidad o confiabilidad del testimonio de la mujer, para luego calibrar su adherencia a la realidad de los hechos apreciada en conjunto con todas las pruebas producidas.

La sentencia examinada, de otro lado, pone énfasis nuevamente en los datos indiciarios (que de existir nos mantendrían fuera de los contornos del análisis del testimonio singular) que pueden prestar respaldo a la declaración de la víctima, los que en ausencia de una perspectiva de género podrían no ser advertidos, remitiéndonos a la calidad del indicio como elemento de corroboración. En estos casos se suele recurrir a los llamados peritajes de credibilidad, los que evidencian los déficit y cuestionamientos a que me he referido, pero que igualmente pueden ser cuestionados desde la perspectiva de su metodología, no exenta de potenciales errores en la interpretación de los datos de evaluación y por estar siempre presentes en su elaboración ciertos sesgos cognoscitivos, como el «sesgo confirmatorio». En el evento de existir un solo elemento de prueba - la declaración de la víctima-, no se cuenta con elementos para la corroboración o contrastación y, por lo mismo, las pericias carecen de virtualidad para apoyar la veracidad del testimonio, razón por la cual su falencia epistémica es fácilmente advertible.

En lo que respecta a los testigos de oídas o testigos de referencia, como dato indiciario que abona a la credibilidad de la víctima en un sistema de libertad de prueba, este elemento de juicio debe ser admitido y practicado en el juicio oral si es relevante para corroborar o refutar las hipótesis formuladas. Pueden aquellos prestar utilidad en el caso que las declaraciones resulten concordantes tanto en lo esencial como en lo periférico, y puede ser un buen índice para testear fiabilidad, fundamentalmente cuando los testigos de oídas son de variada naturaleza como familiares, terceros desconocidos, policías, etcétera, lo que permitiría sortear con éxito el criterio o pauta de suficiencia epistemológica que predica que cuanto más variado y abundante sea el conjunto de elementos de juicio, mayor posibilidad de acierto en la decisión o, dicho de otra forma, de la minimizar la posibilidad de errores (González Lagier, 2018: 19-20). 
Estos testimonios «periféricos» podrían llevar a la elaboración de una prueba sólida para el juez de los hechos a partir de evidencias que no recaen sobre lo que dijo la afectada, sino sobre lo directamente observado por el testigo, como el estado de la vivienda o lugar donde eventualmente habrían ocurrido los hechos, de la víctima, de sus ropas o de su estado de conmoción, los que pueden servir como prueba indiciaria aceptada como prueba de cargo siempre que cumpla determinados requisitos y que sea concluyente (Martin Diz, 2018: 51). ${ }^{14}$

El acopio y el acento en estos elementos de juicio: testigos de oídas, testigos de contexto del hecho y de aquellos a los que me he referido al analizar el primer momento de la actividad probatoria, como evidencias en el sitio del suceso, de su estado, de eventuales elementos o armas utilizadas en la comisión del delito, rastros biológicos, estados de las ropas de la afectada, etcétera, permiten dar nuevos aires al concepto de corroboración necesaria, tanto en la valoración individualizada del acervo probatorio como en la conjunta. Con respecto a la primera, la corroboración implica reforzar los asertos de un testigo (víctima) relativo al hecho principal de una causa, con datos provenientes de una fuente distinta «referidos no directamente a ese hecho, sino a alguna circunstancia que guarda relación con él, cuya constatación confirmaría la veracidad de lo declarado por el primero» (Andrés Ibáñez, 2009: 125).

Con respecto a la corroboración en relación con la valoración conjunta:

Un dato corrobora si versando sobre hechos distintos al principal pero relacionados con él, al ser cruzado con la información inicial relativa al mismo, produce el efecto de conectar también - aunque indirectamente - al imputado con la acción delictiva que se le atribuye (Andrés Ibáñez, 2009: 126).

\section{¿Víctima reforzada y cualificada?}

La Segunda Sala del Tribunal Supremo Español ha dictado recientemente sendas sentencias en que ha acuñado el término de «testigo cualificado» con el fin de referirse a la víctima en los delitos de violencia de género. ${ }^{15}$ En la STS 282 se ha señalado que:

En estos casos, la víctima se encuentra procesalmente en la situación de testigo, pero a diferencia del resto de testigos, es víctima y ello debería tener un cierto reflejo diferenciador desde el punto de vista de los medios de prueba, ya que la introducción de la posición de la víctima en la categoría de mero testigo desnaturaliza la verdadera posición en el proceso penal de la víctima, que no es tan solo quien «ha visto» un hecho y puede testificar sobre él, sino que lo es quien es el sujeto pasivo del

14. Sobre la prueba indiciaria y sus requisitos jurisprudenciales en España, véase Fernández López (2007: 3-4).

15. STS $282 / 2018$ de 13 de junio y $274 / 2018$ de 24 de mayo. 
delito y en su categorización probatoria está en un grado mayor que el mero testigo ajeno y externo al hecho, como mero perceptor visual de lo que ha ocurrido.

Y esto es relevante cuando estamos tratando de la declaración de la víctima en el proceso penal y, sobre todo, en casos de crímenes de género en los que las víctimas se enfrentan a un episodio realmente dramático, cual es comprobar que su pareja, o expareja, como aquí ocurre, toma la decisión de acabar con su vida, por lo que la versión que puede ofrecer del episodio vivido es de gran relevancia, pero no como mero testigo visual, sino como un testigo privilegiado, cuya declaración es valorada por el tribunal bajo los principios ya expuestos en orden a apreciar su credibilidad, persistencia y verosimilitud de la versión que ofrece en las distintas fases en las que ha expuesto cómo ocurrieron unos hechos [...] que se le quedan grabados a la víctima en su visualización de una escena de una gravedad tal, en la que la víctima es consciente de que la verdadera intención del agresor, que es su pareja, o expareja, ha tomado la decisión de acabar con su vida.

Se trata de llevar a cabo la valoración de la declaración de la víctima, sujeto pasivo de un delito, en una posición cualificada como testigo que no solo «ha visto» un hecho, sino que «lo ha sufrido».

Es posible construir una crítica a esta categoría sustentada por el referido tribunal desde varias aristas. En primer lugar, no puede afirmarse que la víctima constituye per se un testigo cualificado, ya que no adquiere calidad de víctima, la eventual afectada con el delito ni de culpable el imputado, sino, y como requisito sine qua non, que se haya dictado sentencia condenatoria ejecutoriada en la causa, ya que en el marco del proceso «el acusado tiene derecho a cuestionar no solo su participación, sino también la existencia misma del hecho y, por tanto, la invocada condición de «víctima», que no precede al proceso, sino que es su consecuencia» (Ramírez, 2018: 19), lo que se contrapone a la posibilidad de considerar ex ante a la víctima como tal.

Por otra parte, la virtualidad probatoria de un relato - su coherencia interna, su grado de detalle y la persistencia en el tiempo- no permite alcanzar la suficiencia necesaria para abonar a la credibilidad de la víctima, ya que su valor de corroboración no puede contrastarse con el mismo relato y ha de, necesariamente, buscar apoyo de corroboración en elementos externos. Aun cuando la deposición de mujer posea las cualidades indicadas, esta prueba no logrará superar el criterio del control epistemológico ya aludido.

En tercer término, es posible advertir una disonancia entre el pronunciamiento traído a colación y la jurisprudencia sostenida por el Tribunal Supremo Español en orden a exigir, como se ha asentado con precedencia, la necesaria corroboración de determinados datos objetivos de carácter periférico, ya que aun cuando no se eleve esta prueba de indicios a la categoría de concluyente de la culpabilidad del acusado, la importancia a los efectos de construir la condena es innegable. Por lo anterior, se han levantado voces que enfáticamente proclaman que: 
Más ajustado a la verdad - aunque menos demagógico - resultaría reconocer que la mera declaración de la víctima no será, en principio, suficiente para desvirtuar la presunción de inocencia del acusado pues, al margen de otras consideraciones (credibilidad subjetiva y persistencia en la incriminación), va a requerir siempre de la práctica de prueba indiciaria sobre determinados datos que aún periféricos y no directamente encaminados a probar la culpabilidad del acusado la doten de una verosimilitud que, a priori, no se le reconoce efectos probatorios (Fuentes, 2017: 378).

\section{La decisión sobre los hechos probados}

El estándar de prueba no es más que una regla de decisión que indica el nivel mínimo de corroboración de una hipótesis para que esta pueda considerarse probada.

La evaluación de las distintas hipótesis plausibles imaginables o de las efectivamente planteadas por las partes en el juicio, de las predicciones que permiten formular la constatación del cumplimiento o incumplimiento de esas predicciones, posibilita al juez la determinación de la probabilidad de que una hipótesis sea verdadera, dados los elementos de juicio disponibles (Ferrer, 2007: 139). El rol del estándar de prueba, entonces, es medir el grado de probabilidad suficiente para dar por probada la hipótesis. Es el umbral que debe ser traspuesto para dar por acreditada la hipótesis de la acusación y derrotar la presunción de inocencia en el juicio penal o para acreditar la hipótesis de inocencia en el caso de alegación de una coartada.

Se ha indicado que el segundo momento de la actividad probatoria se correspondía con el de la racionalidad y que el primero era eminentemente jurídico. Ahora, nuevamente es el turno del derecho, ya que la epistemología no puede indicarle al derecho dónde ubicar el estándar. Sí puede tener cabida para — una vez que se ha establecido- decirle cómo elaborar el grado de exigencia por el que se ha optado o, en otras palabras, actuar señalándole al derecho cuáles son las características que debe tener la definición del estándar de prueba para que así pueda operar en la toma de decisiones y en el control de las adoptadas. Por ejemplo, si se ha optado por una metodología cualitativa inductivista, la epistemología puede mostrar al derecho cuáles son las cualidades que debe buscar en el conjunto de elementos de prueba.

Los errores que se pueden producir en la declaración de hechos probados y que el estándar distribuye son de dos tipos: las falsos negativos, lo que ocurre cuando se da por no probada una hipótesis que es verdadera (se absuelve al acusado que en realidad era culpable), o falsos positivos, lo que tiene lugar cuando se da por probada la hipótesis que es falsa (se condena al acusado pero este es inocente). La ratio entre falsos negativos y falsos positivos es una decisión política-ética, que deberá ser delineada idealmente por la sociedad en su conjunto y que por los bienes jurídicos especiales involucrados en el proceso penal debería expresar una preferencia por los errores negativos frente a los positivos para dar cuenta de esos valores garantistas (Bayón, 2010: 12). 
En materia de los delitos cometidos contra las mujeres por razón de género, cobra especial relevancia este tercer momento del iter valorativo racional, ya que es el instante de decidir si, con la prueba producida - la que se enfrenta a las dificultades probatorias asentadas-, puede entenderse derrotada la presunción de inocencia, es decir, si es posible dictar sentencia condenatoria en contra del agresor.

Las pautas o criterios orientativos elaborados por la jurisprudencia del Tribunal Supremo español se utilizan en una primera aproximación para determinar la credibilidad de la declaración de la víctima en los casos de testimonio singular, no obstante, ellas miran también a calibrar su suficiencia incriminatoria en los términos de virtualidad para derrotar la presunción de inocencia. De este modo, si efectuamos un examen profundo de estos criterios, al exigir el Supremo «el suplementario apoyo de datos objetivos» o "corroboraciones periféricas de carácter objetivo que le doten de aptitud probatoria» en su segunda pauta, lo que requiere es la concurrencia de otros medios de prueba, además de la declaración de la víctima (Rodríguez, 2011: 243), de modo que al parecer, en los casos en que exista stricto sensu únicamente el testimonio de la mujer, ello no será suficiente para estimar colmado el estándar de prueba. Así, se requieren informes médicos de eventuales lesiones, registros de llamadas, declaraciones de parientes, vecinos, policías, etcétera, evento en el cual la condena se sustentará principalmente en la declaración de la víctima, pero no únicamente en ella.

Con respecto a las propuestas de estándar de prueba que elabora la doctrina y que, no obstante su carácter conceptual, pueden servir como propuestas de lege ferenda para dotarlo de operatividad, es propicio traer a colación uno de los que elabora Ferrer (2018b: 417) ${ }^{16}$ Esta regla decisoria incorpora altísimas exigencias para la hipótesis acusatoria, que difícilmente podrán ser satisfechas por la acusación en una abrumadora mayoría de casos en los delitos de violencia machista que evidencien las dificultades probatorias aludidas. Así, es formulado en los siguientes términos:

\section{Estándar de prueba uno}

Para considerar probada la hipótesis de la culpabilidad deben darse conjuntamente las siguientes condiciones:

- La hipótesis debe ser capaz de explicar los datos disponibles integrándolos en forma coherente y las predicciones de nuevos datos que la hipótesis permita formular deben haber resultado confirmadas.

16. En este trabajo, Ferrer propone seis estándares de prueba ordenados de mayor a menor intensidad en cuanto a exigencias probatorias. Además, véase Cátedra de Cultura Jurídica, Jordi Ferrer: Prolegómenos para una teoría sobre los estándares de prueba, 21 de junio de 2018, disponible en bit.ly/2X8igw2. 
- Deben haberse refutado todas las demás hipótesis plausibles, explicativas de los mismos datos, que sean compatibles con la inocencia del acusado, excluidas las meras hipótesis ad hoc.

Me parece que frente a las propuestas que se formulan con desmedido entusiasmo en torno a rebajar el estándar de prueba en los delitos de naturaleza patriarcal, no es posible prima facie responder inflexiblemente negando esa posibilidad. No obstante, la aceptación de aquella flexibilización o rebaja debe pasar necesariamente por una reforma legal que recoja la decisión soberana de reparto del error.

Para avanzar en este acápite y ahondar en el tema analizado (la tercera fase de la actividad probatoria judicial), es indispensable, por cierto, clarificar previamente algunos tópicos erróneos.

En primer término, no es posible identificar el estándar de prueba con la presunción de inocencia como lo hace Ramírez Ortiz (2020: 223), quien predica categórico que «la presunción de inocencia fija el estándar probatorio» y que «no cabe «rebajar» las exigencias del estándar sin desnaturalizar el derecho fundamental [a la presunción de inocencia]». El derecho a la presunción de inocencia es compatible con variados estándares de prueba, ya que presupone la vigencia de un estándar de prueba, pero no implica estándar de prueba alguno (Ferrer, 2018a: 213). Lo anterior se debe a que en su mérito y caso de que existan dudas con respecto a la culpabilidad del acusado, este debe ser absuelto. Esta tajante afirmación deja abierta la pregunta acerca de qué grado de duda sobre la hipótesis de la acusación, en un proceso penal, es compatible con la condena del acusado.

La interrogante no puede ser respondida por la presunción de inocencia, ya que no es ella la que fija el estándar, no obstante que sí presupone la necesidad de contar con un umbral que sea intersubjetivamente controlable para hacer operativa la función de la presunción de inocencia como regla de juicio y poder determinar cuándo se le entiende derrotada por la prueba de cargo.

Es igualmente erróneo lo que sostiene Ramírez (2020: 223) al predicar que «cuando se propone optar por un estándar menos exigente, lo que se propone, en otros términos, es renunciar a la verdad», por cuanto es sabido que en el proceso civil impera mayoritariamente el estándar probatorio de la prueba prevaleciente, siendo este un umbral de mucha menor exigencia que el que rige en materia penal, pero no puede afirmarse como su consecuencia que este procedimiento abdique de su aspiración en orden a la averiguación de la verdad. Lo que sucede es que en este caso se ha optado por repartir la ratio de errores epistémicos de forma más o menos equitativa entre las partes preservando, en la visión racionalista de la prueba, el ideal regulativo de la búsqueda de la verdad.

La epistemología no solo interviene en el reparto del error (determinación de la 
ratio entre falsas absoluciones y condenas injustas), ${ }^{17}$ sino que también está interesada en la disminución de estos. Los instrumentos epistemológicos que actúan en pro del acierto de la decisión deben propender a la conformación de un conjunto de elementos de prueba lo más rico posible desde el punto de vista cualitativo y cuantitativo (desplegándose en esta materia el principio Benthamiano reseñado):

Quién, cómo y cuándo puede proponer la admisión de pruebas, qué pruebas se admiten, cómo se controla su fiabilidad a través de la práctica de la prueba o de la incorporación de otras pruebas sobre la prueba, etcétera, son algunos de los aspectos que inciden en la riqueza del acervo probatorio, lo que, a su vez, afecta la probabilidad de acierto. A mayor y más fiable información, mayor probabilidad de acierto en la decisión sobre los hechos (Ferrer, 2018b: 408).

En relación con lo anterior, es importante mencionar que afirmar lo siguiente no resulta acertado:

Es epistemológicamente correcto fijar un estándar probatorio muy exigente como mecanismo de prevención de los riegos de abuso y error (siempre presentes cuando el Estado que quiere penar reconstruye el pasado histórico y pretende establecer como verdad el resultado de su propia reconstrucción) (Ramírez, 2020: 224).

El motivo es que la determinación del nivel de exigencia probatoria que debe colmar el estándar de prueba no incide en la disminución de los errores, sí en su distribución.

Que elevar el estándar de prueba disminuya los errores con respecto a la declaración de hechos probados es una afirmación sesgada, ya que implica disminuir cierto tipo de errores en desmedro de otros. En concreto, disminuye el número de condenas injustas y aumenta el número de absoluciones falsas, lo que conforme al compromiso epistemológico del proceso implica igualmente un fracaso en su finalidad estructural de averiguación de la verdad.

Clarificados los puntos anteriores, creo que sería posible operar con estándares de prueba diferenciados - como lo esboza Ferrer (2007: 140) —, con el fin de aceptar una hipótesis como probada en ciertos tipos de delitos que exhiben dificultades probatorias, como ocurre en los casos de violencia contra la mujer en razón de género, afirmación que - como se dijo- reconoce como necesaria su consagración normativa. Este autor ofrece seis estándares de prueba que ordena de mayor a menor exigencia, siendo el primero de ellos al que se ha hecho alusión al inicio de este acápite.

Es insoslayable expresar que, en el tema que estoy analizando, confluyen varios

17. Dijimos que la fijación del estándar de prueba es una decisión política-jurídica-ética, pero que la epistemología puede ayudar al sistema jurídico señalando cómo debe ser diseñado el estándar de prueba por el que se ha optado. 
factores que deben ser tenidos en cuenta a la hora de optar por un estándar de decisión, lo que impone desechar los tres o cuatro últimos de menor exigencia propuestos por el autor citado. Entre estos factores que inciden en la elección del estándar se presentan las cargas y costos que deben asumir tanto la acusación (y por ende la víctima) como el acusado al optar por estándares de fuertes exigencias o por aquellos que las debilitan, en los casos de absoluciones falsas y condenas injustas, respectivamente, los que son evidentes.

En los delitos de violencia patriarcal, las particularidades y dificultades probatorias que de ordinario acompañan a su juzgamiento redundan en una gran cantidad de sentencias absolutorias, lo que produce que se levanten consignas con respecto a una eventual rebaja de la regla de decisión. No obstante, la definición del estándar no es fácil, ya que sobre todo en los delitos que conllevan penas de gran entidad existen igualmente poderosas razones para mantener estándares de prueba de un alto nivel de exigencia.

Creo que con lo anterior he desechado o al menos puesto en duda la afirmación que se asume como dogma incontrovertible en orden a que el estándar de prueba no puede ser flexibilizado bajo ningún respecto, y es en el marco de esta conclusión que podrían tener operatividad algunos de los demás estándares de decisión propuestos por Ferrer o los que ofrezcan otros autores. El de segunda mayor intensidad es el siguiente.

\section{Estándar de prueba dos}

Para considerar probada una hipótesis sobre los hechos deben darse conjuntamente las siguientes condiciones:

- La hipótesis debe ser capaz de explicar los datos disponibles, integrándolos en forma coherente, y las predicciones de nuevos datos que la hipótesis permita formular deben haber resultado confirmadas.

- Debe haberse refutado la hipótesis alternativas formuladas por la defensa, si es plausible, explicativa de los mismos datos y compatible con la inocencia del acusado, excluidas las meras hipótesis ad hoc.

Asumo que puede replicarse a la alternativa expuesta que en Chile y en muchos países en que rige el derecho continental, se ha adoptado la fórmula heredada del common law más allá de toda duda razonable como estándar de prueba en materia penal, la que ha tenido acogida normativa en varios de nuestros ordenamientos jurídicos (artículo 340 del Código Procesal Penal de Chile) y que sería incompatible con reformulaciones que eventualmente podrían contrariar la regla citada, pudiendo replicarse a lo anterior que la determinación del estándar es una decisión política-ética, por lo que democráticamente la sociedad puede optar por la consagración normativa 
de umbrales diferenciados que recojan las dificultades probatorias que exhiben los delitos en estudio, entre otros.

Para dar operatividad a lo formulado, que reconozco no está exento de dificultades, los estándares por los que se decante el sistema legal deben ser ineludiblemente objetivos, es decir, independientes de las creencias del juzgador y, por tanto, intersubjetivamente controlables. Además, deben estar establecidos de antemano por el legislador.

Por cómo opera el cognoscitivismo en la reducción del error a la luz de los criterios de racionalidad general y tratándose de los casos de testimonio singular en sentido estricto, existen razones epistémicas que inhiben la consideración de que en ellos la prueba tenga la virtualidad de derrotar la presunción de inocencia (Di Corleto, 2017: 305), aserto que se ve reforzado con la exigencia formulada por el Tribunal Supremo Español en orden a la insoslayable necesidad de corroboración mediante datos periféricos, lo que impediría «en puridad reconocer viabilidad al testimonio de la víctima para desvirtuar la presunción de inocencia cuando es la única prueba de cargo practicada» (Fuentes, 2020: 375), lo que posee su justificación en la circunstancia de que de no mediar estos elementos externos, se contaría únicamente con la declaración de la víctima, la cual solo tendría su propio reflejo para ser confrontada. ${ }^{18}$

La conclusión que puede ser extraída de lo precedentemente indicado es que ineludiblemente deben redoblarse los esfuerzos desplegados en la primera etapa de la actividad probatoria —-formación del acervo de los elementos de juicio-, donde el enfoque concernido en este trabajo posee potencialmente gran rendimiento, sobre todo desde la perspectiva heurística. Así, lo descubierto en estas etapas incipientes rendirá frutos al momento de valoración en sentido estricto e igualmente al momento de decidir sobre la culpabilidad o inocencia del acusado y justificar esa decisión.

\section{Conclusión}

Teniendo en cuenta las enormes dificultades que representa el juzgamiento de los delitos de género, tanto al momento de la recolección de elementos de juicio que configurarán el acervo probatorio como en los momentos de la valoración en sentido estricto de ese conjunto y de aplicación del estándar de prueba penal más allá de toda duda razonable, no resulta aceptable descartar acríticamente las propuestas que se erigen como contrapeso a la gran cantidad de situaciones que terminan en absoluciones erróneas.

Así, la impunidad denunciada se produce en un gran porcentaje de casos porque la víctima se sujeta a su derecho a guardar silencio o se retracta de su declaración

18. Sobre una férrea defensa acerca de la falta de virtualidad del testimonio único para la derrota de la presunción de inocencia, véase Sancinetti (2013: 23-39). 
inculpatoria deponiendo en favor de la tesis absolutoria, porque el fenómeno de la violencia contra la mujer va acompañado habitualmente de sentimientos de temor al victimario o de ambivalencia hacia él, por lo que la declaración de la afectada debe valorarse teniendo en cuenta si entre ella y su agresor existe o existió una relación asimétrica de poder en que deberán considerarse especialmente posibles contactos entre ellos y la existencia de amenazas o manipulaciones que alteren el relato, a la par de las consecuencias negativas que pueda implicar la denuncia en los planos económicos, familiar o social, lo que no debe presumirse por el solo hecho de tratarse de un delito de género, sino que probarse y justificarse de forma completa y detallada en la motivación de la sentencia a efectos de su control.

El especial contexto en que se despliegan estos ilícitos, lejos de eximir a los entes encargados de su persecución de realizar investigaciones completas por estimar que la declaración de la víctima por el solo hecho de haber sufrido los efectos del delito la pone en una situación privilegiada en cuanto a su credibilidad y suficiencia incriminatoria, los obliga a efectuar la indagación con enfoque de género, lo que significa ampliar la recolección de las pruebas potencialmente relevantes y ser especialmente cuidadosos en su conservación, procurando no tratar a la víctima como una evidencia más, brindándole contención, apoyo y protección oportuna en su consideración como ser humano afectado significativamente en su dignidad y en su derecho fundamental a vivir una vida libre de violencia, pero también con el propósito de que realice una declaración completa, produciendo información de calidad en miras a la eficacia de la investigación y de la prueba.

La perspectiva de género se muestra como una herramienta metodológica útil con el fin de poner el acento en la primera fase del iter valorativo y posee una gran relevancia heurística a fin de imaginar o proponer hipótesis desde esta perspectiva en la sede investigativa, las que en las fases siguientes deben ser corroboradas, lo que conducirá a recabar la mayor cantidad de datos de gran calidad informativa y de relevancia tanto en lo que dice relación directa con el hecho a probar, como con el contexto en que ha tenido lugar el delito, que debe igualmente acreditarse.

Al momento de valorar los datos probatorios, la herramienta metodológica a la que me he dedicado impone, en primer término, identificar las máximas de experiencia de contenido patriarcal y que, sin perjuicio de presentarse como conocimiento compartido por un grupo significativo de la población, únicamente solapan prejuicios y preconcepciones de lo que se espera sea el comportamiento normal y aceptable de la mujer. Una vez identificadas estas generalizaciones prejuiciosas y sin sustento empírico, deben ser desactivadas y dejadas de lado, facilitando así una valoración no estereotipada de la prueba.

Aun cuando se presenten como muy tentadoras las ideas de rebajar el estándar de prueba en demasía - y asimilarlo incluso al estándar que impera en materia civilcon el fin de estrechar el espacio de impunidad en estos delitos, esto no resulta viable. 
Debido a lo anterior señalo nuevamente que el énfasis se debe volcar a la primera fase, lo que implica el desarrollo de investigaciones policiales inteligentes, completas y eficaces, siempre al alero de la perspectiva de género. Así, tampoco es viable invertir la carga de la prueba al otorgar a la víctima un estatus reforzado por el solo hecho de serlo, lo que resulta evidentemente incompatible con la presunción de inocencia y que, de hacerse efectivo, implicaría un socavamiento profundo de las bases del sistema procesal penal democrático.

Pese a lo dicho, también es posible afirmar que no constituye una conclusión petrificada la que predica la imposibilidad de establecer estándares diferenciados en el caso de ilícitos que conllevan dificultades probatorias como los que he analizado, opción que debe ser objeto de una decisión legislativa que recoja el reparto de errores epistémicos en la proporción por la que la sociedad se ha decantado, efectuando el adecuado balance entre los bienes jurídicos en juego. Reconozco que ello no resulta exento de dificultades, sin embargo, la propuesta es que vía lege ferenda se establezcan reglas de decisión que no impliquen la asimilación al estándar de prueba prevaleciente, pero que sean de una aceptable menor intensidad. De esta forma, eventualmente podría conciliarse la obligación del Estado de proteger a los ciudadanos y ciudadanas para que no se comentan delitos en su contra y la determinación adecuada de la ratio entre falsas absoluciones y condenas injustas.

En materia de violencia patriarcal, estimo que se hace aún más intenso el compromiso epistemológico del proceso, ya que su término mediante soluciones pactadas está vedado en la mayoría de estas causas, atendida la asimetría en la relación que vincula a la mujer y al victimario o por la gravedad de las penas contempladas para su comisión, por lo que resulta ineludible conocer la verdad de lo sucedido, cobrando así la institución probatoria y sus momentos un protagonismo indiscutible.

\section{Referencias}

Accatino, Daniela (2010). «El modelo legal de justificación de los enunciados probatorios y su control a través del recurso de nulidad». En Formación y valoración de la prueba en el proceso penal (pp. 119-143). Santiago, Legal Publishing.

Aguilera, Edgar (2018). «El germen contraepistémico del garantismo penal extremo

(O del elefante en la sala que pocos están dispuestos a ver)». En Carmen Vázquez (coordinador), Hechos y razonamiento probatorio (pp. 85-104). México: CEJI.

ANDrÉz IbÁÑEz, Perfecto (2007). «Sobre el valor de la inmediación. (Una aproximación crítica)». En En torno a la jurisdicción. Buenos Aires: Editores del Puerto.

-. (2009). «La supuesta facilidad de la testifical». En Prueba y convicción en el proceso penal. Buenos Aires: Hamurabi.

Araya, Marcela (2018). Recurso de nulidad y control racional de la prueba. De la epistemología a la praxis. Santiago: Librotecnia. 
-. (2020). «La motivación del juicio sobre los hechos como condición ineludible del control de la calidad epistemológica de las conclusiones probatorias en Chile». En Francisco Hermosilla y Rodrigo Cerda (coordinadores), Reflexiones sobre la prueba judicial. En homenaje al profesor Manuel Miranda Estrampes (pp. 110-137). Santiago: Librotecnia.

Armenta, Teresa (2011). La prueba ilícita. (Un estudio comparado). Madrid: Marcial Pons. BAYón, Juan Carlos (2010). «Epistemología, moral y prueba de los hechos: hacia un enfoque no benthamiano». Revista Jurídica Mario Alario D’Filippo, 2 (4): 6-30). Disponible en bit.ly/3dbjwnM.

De Paula Ramos, Víctor (2019). La prueba testifical. Marcial Pons: Madrid.

Di CoRleto, Julieta (2017). «Igualdad y diferencia en la valoración de la prueba: estándares probatorios en casos de violencia de género». En Julieta Di Corleto (compiladora), Género y justicia penal (pp. 409-433). Buenos Aires: Didot.

Di Corleto, Julieta y Piqué, María Luisa (2017). «Pautas para la recolección y valoración de la prueba con perspectiva de género». En Luz Cynthia Silva (coordinadora), Género y derecho penal (pp. 285-307). Lima: Instituto Pacífico.

Duce, Mauricio (2010). «Admisibilidad de la prueba pericial en los juicios orales: Un modelo para armar». En Daniela Accatino (editora), Formación y valoración de la prueba en el proceso penal (pp. 45-86). Santiago: Legal Publishing.

FernándeZ, Mercedes (2007). «La valoración de pruebas personales y el estándar de la duda razonable». Cuadernos electrónicos de filosofía del derecho, 15: 1-12. Disponible en bit.ly/2ZJDQsu.

Ferrer, Jordi (2007). La valoración racional de la prueba. Madrid: Marcial Pons.

-. (2010). «La prueba es libertad pero no tanto: Una teoría teoría de la prueba cuasibenthamiana». En Daniela Accatino (editora), Formación y valoración de la prueba en el proceso pena (pp. 3-19)l. Santiago: Legal Publishing.

-. (2018a). «Derecho a la prueba y racionalidad de las decisiones judiciales». En Prueba y racionalidad en las decisiones judiciales. Santiago: Prolibros.

-. (2018b). «Prolegómenos para una teoría sobre el estándar de prueba. El test case de la responsabilidad del Estado por prisión preventiva errónea». En Diego Papayanis y Esteban Pereira (editores), Filosofía del derecho privado (pp. 401-430). Madrid: Marcial Pons.

Fuentes, Olga (2017). «La prueba de la violencia de género. Cuestiones procesales fundamentales y nuevas tecnologías». En Luz Cynthia Silva (coordinadora), Género y derecho penal (pp. 371-407). Lima: Instituto Pacífico.

-. (2020). «La perspectiva de género en el proceso penal. ¿Refutación? de algunas conjeturas sostenidas en el trabajo de Ramírez Ortiz «El testimonio único de la víctima en el proceso penal desde la perspectiva de género»». Quaestio facti. Revista internacional sobre razonamiento probatorio, 11: 271-284. 2020. Disponible en bit.ly/2ZIYmcM. 
GASCón, Marina (2004). Los hechos en el derecho: Bases argumentales de la prueba. Madrid: Marcial Pons.

González Lagier, Daniel (2018). «Distinciones, estipulaciones y sospechas sobre los criterios de valoración y los estándares de prueba». En Johann Benfeld y Jorge Larroucau (editores), La sana crítica bajo sospecha (pp. 15-32). Valparaíso: Ediciones Universitarias de Valparaíso.

Hopp, Cecilia (2017). ««Buena madre», «buena esposa», «buena mujer»: abstracciones y estereotipos en la imputación penal». En Julieta Di Corleto (compiladora), Género y justicia penal (pp. 15-46). Buenos Aires: Didot.

IgARTUA, Juan (2003) La motivación de las sentencias, imperativo constitucional. Madrid: Centro de Estudios Políticos y Constitucionales.

-. (2004). El Comité de Derechos Humanos, la casación penal española y el control del razonamiento probatorio. Madrid: Thomson Civitas.

JARA, Francisco (2012) «El derecho a la prueba y la prueba ilícita en el derecho internacional de los Derechos Humanos». Revista de Derecho Público, 77: 387-404. Disponible en bit.ly/2Xbs3S9.

Lamas, Marta (2002). Cuerpo: diferencia sexual y género. México: Taurus.

LAUDAN, Larry (2005). «Por qué un estándar de prueba subjetivo y ambiguo no es un estándar de prueba». DOXA, 28: 95-113. Disponible en bit.ly/2AbUSof.

Martin Diz, Fernando (2018). «Presunción de inocencia en procesos penales por violencia de género». Ius et Praxis, 24 (3): 19-66. Disponible en bit.ly/36H2oUj.

Montesinos, Ana (2017). «Especificidades probatorias en los procesos por violencia de género». Revista de Derecho Penal y Criminología, 17: 127-165. Disponible en bit.ly/2yABbGa.

Picó I Junoy, Joan (2009). «El derecho a la prueba en el proceso penal. Luces y sombras». Justicia: Revista de derecho procesal, 1-2: 99-156. Disponible en bit. ly/3dkSTgh.

RAMíREZ, José Luis (2018). «El testimonio único de quien afirma ser víctima desde la perspectiva de género». Revista Juezas y Jueces para la Democracia, Boletín Comisión Penal, 2 (10): 9-23. Disponible en bit.ly/2 $\mathrm{M}_{3} \mathrm{Q}_{3} \mathrm{QD}$.

-. (2020). «El testimonio único de la víctima en el proceso penal desde la perspectiva de género». Quaestio facti. Revista internacional sobre razonamiento probatorio, 1: 201-246. Disponible en bit.ly/2AeiCZ3.

RodrígueZ, Sonia (2011). «La prueba en los supuestos de violencia de género». Télos, 18 (1-2): 231-246. Disponible en bit.ly/2M5gLIw.

RuedA, Yolanda (2018). «Los estereotipos de género en el proceso penal». Revista Juezas y Jueces para la Democracia, Boletín Comisión Penal, 1 (10): 12-20. Disponible en bit.ly/3c7V31d.

SAnCinetTi, Marcelo (2013). «Testimonio único y principio de la duda». InDret. Revista para el Análisis del Derecho, 3: 23-39. Disponible en bit.ly/36zqsbL. 
SoRdi, Bárbara (2018). Violencia contra la mujer. Prevención: Programas de rehabilitación, análisis internacional. Buenos Aires: B de F.

Subijana, Ignacio (2018). «La perspectiva de género en el enjuiciamiento de los delitos de violencia del hombre sobre la mujer». Revista Juezas y Jueces para la Democracia, Boletín Comisión Penal, 1 (10): 27-39. Disponible en bit.ly/2XBswf9.

Taruffo, Michele (2008). La prueba. Madrid, Marcial Pons.

-. (2010). Simplemente la verdad. El juez y la construcción de los hechos. Trad. por Daniela Accatino. Madrid, Marcial Pons.

ZÚÑIGA, Yanira (2013). «Igualdad y diferencia en la teoría feminista: el debate conceptual sobre la justicia, la familia y la diversidad». En Fernando Muñoz (editor), Igualdad, inclusión y derecho. Lo político, lo social y lo jurídico en clave igualitaria (pp. 193-214). Santiago: Lom.

-. (2018). «Cuerpo, género y derecho. Apuntes para una teoría crítica de las relaciones entre cuerpo, poder y subjetividad». Ius et Praxis, 24 (3): 209-254. Disponible en bit.ly/2AaIVPR.

\section{Sobre la autora}

Marcela Paz Araya Novoa es abogada, licenciada en Ciencias Jurídicas y Sociales por la Universidad de Concepción, magíster en Derecho Penal y Procesal Penal por la Universidad Austral de Chile y doctora en Derecho por la Universidad de Girona de España. Además, es profesora de Derecho Probatorio en la Universidad Austral de Chile, sede Puerto Montt, y jueza de garantía en la misma ciudad. Sus correos electrónicos son marcela.araya.novoa@gmail.com y marcela.araya@uach.cl. (D) https:// orcid.org/0000-0002-6971-9692. 
